\title{
Adolescent self-harm: think before prescribing
}

\section{Joel King \\ Consultant child and adolescent psychiatrist and Psychiatry training coordinator, Professorial Unit, The Melbourne Clinic \\ Senior lecturer, Department of Psychiatry, University of Melbourne}

\section{Sonja Cabarkapa \\ Psychiatry registrar, St Vincent's Hospital, Melbourne}

\section{Fiona Leow}

Consultant psychiatrist, Eating Disorders Unit, Royal Melbourne Hospital

\section{Keywords}

drug overdose, self-inflicted injury, suicide

Aust Prescr 2019;42:90-2 https://doi.org/10.18773/ austprescr.2019.023

\section{SUMMARY}

The assessment of self-harm in adolescence should include identifying medical complications and any underlying psychiatric conditions.

Changes in the frequency, type, and severity of self-harm can signify increasing suicidality and progression towards lethal action. As 30\% of adolescent self-harm involves an overdose of prescription drugs, prescribing limited quantities and having the parents hold the supply can decrease this risk. Individual psychological therapies are first line. They can be combined with school and parental involvement.

There is very little evidence supporting the use of psychotropic drugs for treating adolescent self-harm.

\section{Introduction}

Adolescent self-harm is a common but complex issue faced by GPs. The second Australian Child and Adolescent Survey of Mental Health and Wellbeing found $10 \%$ of teenagers reported that they had previously harmed themselves. Self-harm was twice as high in females than in males. ${ }^{1}$ The survey defined self-harm as deliberately hurting or injuring oneself without intent to suicide, often done secretly. This encompasses both self-injury and self-poisoning. Selfinjury refers to deliberate, self-inflicted destruction of body tissue resulting in immediate damage, without suicidal intent, including cutting, scratching and selfbattery. ${ }^{2}$ Self-poisoning refers to intentionally taking a poisonous substance believing that it will be noxious. ${ }^{3}$

\section{Causes of self-harm}

There are several aetiological theories for self-harm. The distraction hypothesis suggests self-harm diverts attention from emotional pain to physical sensations. Another theory describes self-harm leading to endogenous opioid release and an analgesic effect. The self-verification concept proposes self-harm communicates adolescents' negative views about themselves to others. Accordingly, self-harm is best seen as a heterogeneous phenomenon with complex internal and external factors. ${ }^{4}$

Contextual factors include sexual abuse, bullying, sexuality difficulties, poor academic performance, school refusal, family dysfunction, abusive online contacts, and self-harming peers. The nature of stressors varies with age. Younger adolescents commonly describe familial stress. Older adolescents are more likely to describe peer-related stress. ${ }^{5}$

\section{Assessment}

The initial assessment should exclude medical complications, such as neurovascular damage and infection. If the history shows changes in selfharm frequency, type and severity, this can signify increasing suicidality and progression towards taking lethal action.

It is important to screen for psychiatric disorders that often first present in adolescence, such as depression, anxiety disorders, eating disorders, emerging psychosis, and substance use disorders. Enquiring about the adolescent's ways of coping with different stresses may reveal emerging personality traits and disorders. However, caution is needed around making definitive diagnoses due to ongoing identity formation and frontal cortical development in adolescence.

These processes contribute to maturation of reasoning, goal setting and impulse control. ${ }^{6}$ Active psychiatric disorders such as depression impair cognition and problem-solving and can mistakenly give the impression of a personality disorder. A thorough developmental history and psychiatric referral may assist this differentiation. Adolescents with a suspected emerging psychosis should be assessed urgently, especially if there is a family history of mood or psychotic disorders.

\section{Management}

Adolescents are more likely to reduce their self-harm behaviours when underlying stressors are addressed or when they learn other ways of coping. Given that self-harm is often a coping strategy taken up in desperation, simply telling the adolescent to stop is unhelpful and invalidating. 
Many mental disorders presenting in adolescence can be treated with psychological therapy and unnecessary prescribing can be avoided. Some schools have excellent wellbeing coordinators and counsellors who may be able to provide a safe schoolbased space and basic psychological assistance. An external therapist should be sought for more structured therapies such as cognitive or dialectical behavioural therapy. Both the Royal Australian and New Zealand College of Psychiatrists and the Australian Psychological Society websites have directories of practitioners. ${ }^{7,8}$ Headspace services have psychologists and sometimes a visiting child and adolescent psychiatrist. ${ }^{9}$ Public child and youth mental health services usually become involved in more severe, complex cases with significant family dysfunction, ongoing self-harm, case-management needs, and coordination between multiple agencies, such as child protection.

Poor sleep is correlated with self-harm. Sleep hygiene education should be provided. ${ }^{10}$

\section{Parental involvement}

Parents may be needed for practical issues, such as booking and paying for appointments, and addressing stressors that the adolescent cannot solve on their own. These include family conflict, unreasonable school or parental expectations, and bullying. Some parents require separate therapy where they learn to contain their own anxiety and provide support and validation for their teenager. This can run alongside individual therapy for the adolescent, with all clinicians in regular contact to ensure a consistent understanding of the clinical situation and management plan.

\section{Confidentiality}

The adolescent may not want their parents to know about their self-harm, usually fearing their parents will not understand, blame them, or simply tell them to stop their behaviour. While respecting these concerns, involving parents can help the adolescent feel less alone and better supported. Such fears should be addressed by speaking first with the adolescent about a shared, non-judgemental understanding of the behaviour, and offering to speak with the parents while the adolescent is in the room. Negotiating what the adolescent is willing to share with their parents is crucial. This may take several sessions before sufficient trust is built for the adolescent to involve their parents.

Occasionally, there is extremely dangerous self-harm which requires acute intervention. This can include urgent involuntary treatment under the relevant mental health act, usually when the patient cannot give informed consent, refuses treatment, and poses an acute risk to themselves or others. In these situations, the GP should also consider informing the parents, which may be against the adolescent's wishes, and explain the reasons for doing so. This requires a careful balance between respecting doctor-patient confidentiality and supporting crucial caregivers."

\section{Preventing harm}

Identifying early warning signs and formulating an agreed plan with all parties can reduce further episodes of self-harm. A useful tool is the traffic light system where the adolescent identifies what feelings and behaviours occur at different colours (see Table) and what the responses should be at each stage. ${ }^{12}$ The patient, family and clinicians follow the plan and update it if required.

The traffic light approach can ensure a consistent management response when the overwhelmed adolescent is unlikely to produce a coherent description of their emotional state and needs. This is due to cortical dysfunction of higher brain regions, with reliance on lower, brainstem-level responses. At this time, a lengthy discussion about stressors and feelings is likely to cause more distress. It is better to talk when patients return to 'green' and can reflect

\section{Table An example of a traffic light management plan for the prevention of adolescent self-harm}

\begin{tabular}{|c|c|c|}
\hline $\begin{array}{l}\text { Early } \\
\text { warning } \\
\text { signs }\end{array}$ & \multicolumn{2}{|c|}{$\begin{array}{l}\text { - Not sleeping well } \\
\text { - Not attending my extracurricular activities, e.g. soccer } \\
\text { - Becoming irritable at small things }\end{array}$} \\
\hline Traffic light & My thoughts and behaviour & My plan \\
\hline Green & $\begin{array}{l}\text { - Stress level minimal } \\
\text { - Going to school } \\
\text { - Engaging with family } \\
\text { and friends } \\
\text { - Few thoughts of self-harm }\end{array}$ & $\begin{array}{l}\text { - Continue with sleep hygiene } \\
\text { - Write in journal when feeling } \\
\text { stressed } \\
\text { - Play soccer with friends }\end{array}$ \\
\hline Orange & $\begin{array}{l}\text { - Stress level moderate } \\
\text { - Increased time checking } \\
\text { social media } \\
\text { - Comfort eating } \\
\text { - Withdrawing to my room }\end{array}$ & $\begin{array}{l}\text { - Listen to my favourite music } \\
\text { - Use rubber band technique } \\
\text { - Go for a short walk with Dad } \\
\text { and the dog }\end{array}$ \\
\hline Red & $\begin{array}{l}\text { - Feeling overwhelmed } \\
\text { - 'I can't problem-solve or } \\
\text { talk anymore' } \\
\text { - 'I hate myself and the world' } \\
\text { - 'I want to cut myself now' }\end{array}$ & $\begin{array}{l}\text { - Hold ice cubes tightly } \\
\text { - Parents, please sit with me but } \\
\text { don't talk to me } \\
\text { - Parents, ensure no access } \\
\text { to blades } \\
\text { - Parents, reduce overall } \\
\text { stimulation for me } \\
\text { - Parents, help me call Lifeline }\end{array}$ \\
\hline
\end{tabular}


more clearly. Phrases with 'What led to ...' and 'And then what happened?' may be more acceptable than questions starting with 'Why?'

Education and harm minimisation are important tools, especially for adolescents with repetitive patterns of self-harm. Most adolescents are unaware of the potential for self-harm to cause serious damage, morbidity or even death. ${ }^{13}$ Preventing harm may involve offering a less dangerous alternative that achieves a similar sensation. Examples include flicking a rubber band around the wrist, temporarily holding ice cubes, or doing exercise such as push-ups. Tailored distraction techniques such as listening to music or playing a game can be helpful. Restricting access to implements, such as razor blades, knives, pills and firearms, is recommended but insufficient alone. These restrictions are often circumvented by desperate adolescents.

\section{Drug therapy}

There are no pharmacological trials focusing on reducing repetitive deliberate self-harm in children or adolescents. In adults, the small number of randomised controlled trials found that drug treatment does not reduce the risk of repeated self-harm. ${ }^{14}$

Psychotropic drugs may have a role in treating severe underlying psychiatric disorders that do not respond to psychological interventions, but these cases should be referred to a child and adolescent psychiatrist. The limited evidence base should be explained to the patient and family. If a prescription is issued, prescribe limited quantities and ask the parents to hold and dispense the drugs as this can reduce the risk of overdose. ${ }^{15}$

About $30 \%$ of self-harm is by overdose with prescription drugs, most commonly benzodiazepines, antidepressants and amphetamines. ${ }^{16,17}$ Medicines are often combined with alcohol and recreational drugs in impulsive overdoses. ${ }^{18}$ This is unsurprising as many of these substances reduce inhibition. Motivational interviewing and limiting access are reasonable first steps to reduce the abuse of these substances.

\section{Conclusion}

Adolescent self-harm represents a common group of behaviours that are best addressed through psychological means. This may involve the family and the school. Prescription drugs have nearly no evidence supporting their use in this age group and should be avoided. $<$

Joel King has received honoraria for providing independent medical education at a symposium funded by Servier.

\section{REFERENCES}

1. Lawrence D, Johnson S, Hafekost J, Boterhoven de Haan K, Sawyer M, Ainley J, et al. The mental health of children and adolescents: report on the second Australian Child and Adolescent Survey of Mental Health and Wellbeing. Canberra: Commonwealth of Australia; 2015. http://www.health.gov.au/internet/main/publishing.nsf/ Content/mental-pubs-m-child2 [cited 2019 May 1]

2. Swannell SV, Martin GE, Page A, Hasking P, St John NJ. Prevalence of nonsuicidal self-injury in nonclinical samples: systematic review, meta-analysis and meta-regression. Suicide Life Threat Behav 2014;44:273-303. https://doi.org/ 10.1111/sltb.12070

3. Bancroft JH, Skrimshire AM, Reynolds F, Simkin S, Smith J. Self-poisoning and self-injury in the Oxford area. Epidemiological aspects 1969-73. Br J Prev Soc Med 1975;29:170-7. https://doi.org/10.1136/jech.29.3.170

4. Kirtley OJ, O'Carroll RE, O'Connor RC. Pain and self-harm: a systematic review. J Affect Disord 2016;203:347-63. https://doi.org/10.1016/j.jad.2016.05.068

5. Hazel NA, Oppenheimer CW, Technow JR, Young JF, Hankin BL. Parent relationship quality buffers against the effect of peer stressors on depressive symptoms from middle childhood to adolescence. Dev Psychol 2014;50:2115-23. https://doi.org/10.1037/a0037192

6. Crews F, He J, Hodge C. Adolescent cortical development: a critical period of vulnerability for addiction. Pharmacol Biochem Behav 2007;86:189-99. https://doi.org/ 10.1016/j.pbb.2006.12.001

7. Your Health in Mind. Find a psychiatrist [Internet] Melbourne: The Royal Australian \& New Zealand College of Psychiatrists; 2019. https://www.yourhealthinmind.org/ find-a-psychiatrist [cited 2019 May 1]

8. Australian Psychological Society. Find a psychologist [Internet]. Melbourne: APS; 2018. https://www.psychology.org.au/ Find-a-Psychologist [cited 2019 May 1]

9. Headspace [Internet]. Headspace National Youth Mental Health Foundation Ltd; 2019. http://www.headspace.org.au [cited 2019 May 1]

10. Hysing M, Sivertsen B, Stormark KM, O'Connor RC. Sleep problems and self-harm in adolescence. Br J Psychiatry 2015;207:306-12. https://doi.org/10.1192/bjp.bp.114.146514

11. Mental Health Act. 2014. No. 26 of 2014. Authorised version no. 018 incorporating amendments as at 1 April 2018. http://www.legislation.vic.gov.au/Domino/Web_Notes/ LDMS/PubStatbook.nsf/f932b66241ecf1b7ca256e92000e 23be/0001F48EE2422A10CA257CB4001D32FB/\$FILE/14026abookmarked.pdf [PDF] [cited 2019 May 1]

12. Croucher S, Williamson GR. Risk assessment in mental health: introducing a traffic light system in a community mental health team. Open Nurs J 2013;7:82-8. https://doi.org/10.2174/1874434620130529004

13. Fortune SA, Hawton K. Deliberate self-harm in children and adolescents: a research update. Curr Opin Psychiatry 2005;18:401-6. https://doi.org/ 10.1097/01.yco.0000172059.55778.c9

14. Saunders KE, Smith KA. Interventions to prevent self-harm: what does the evidence say? Evid Based Ment Health 2016;19:69-72. https://doi.org/10.1136/eb-2016-102420

15. Carter G, Page A, Large M, Hetrick S, Milner AJ, Bendit N, et al. Royal Australian and New Zealand College of Psychiatrists clinical practice guideline for the management of deliberate self-harm. Aust N Z J Psychiatry 2016;50:939-1000. https://doi.org/10.1177/0004867416661039

16. De Leo D, Heller TS. Who are the kids who self-harm? An Australian self-report school survey. Med J Aust 2004;181:140-4.

17. Australian Bureau of Statistics. 3303.0 - Causes of death, Australia, 2016 [Internet]. Canberra: ABS; 2018. http://www.abs.gov.au/ausstats/abs@.nsf/Lookup/ by\%20Subject/3303.0 2016 Main\%20Features Drug\%20 Induced\%20Deaths\%20in\%20Australia 6 [cited 2019 May 1]

18. Pompili M, Serafini G, Innamorati M, Biondi M, Siracusano A, Di Giannantonio $M$, et al. Substance abuse and suicide risk among adolescents. Eur Arch Psychiatry Clin Neurosci 2012;262:469-85. https://doi.org/10.1007/s00406-012-0292-0 